\title{
A synopsis of the mental health concerns of university students: Results of a text-based online survey from one Australian university
}

\begin{abstract}
Within the university community, student demographic data highlights a high level of cultural diversity and an "at-risk population" for the onset of mental health problems. Moreover, the transition to higher education is itself associated with a range of emotional, social and academic demands that can cause psychological distress. Therefore, at any one time a substantial number of students may be attempting to complete university studies while managing problematic symptoms, behaviours, or an emerging, or diagnosed, mental disorder. The aim of this paper is to provide a snap shot of these students' experiences to enable strategic planning of future university support services. Of particular importance was the identification of facilitators and barriers that this group of students faced while engaged in university life.

Participants were 1378 students enrolled at a Western Australian university who accessed a text-based online survey during May 2009. The students provided descriptions of the range of problematic symptoms, behaviours and/or disorders that were causing interference with their lives, and university career. Not surprisingly, the most commonly identified disorders with the participant population were depression, anxiety, and stress-related concerns. More than half the sample had not sought professional help for their concerns. The results highlight the fact that universities are well placed to have a major role in improving the pathways to primary care and early intervention for students with an emerging, or diagnosed, mental health problem, and to identify and support students trying to manage the "normal" psychological demands associated with higher education.
\end{abstract}

Keywords: mental health problems, mental illness, psychological stress

\section{Introduction}

University communities contain an "at-risk population" for mental ill-health. This occurs because the age at which young adults are engaged in higher education tends to coincide with the age of onset of a number of mental disorders, such as anxiety, depression and schizophrenia, as well as substance abuse problems (Kessler et al., 2007). The transition to higher education is also associated with a range of emotional, social and academic demands that may increase students' levels of psychological distress (Palmer \& Puri, 2006). The presence of mental health problems in university students is increasingly highlighted in international literature as an area of importance. Moreover, mental health problems in this cohort appear to be increasing in numbers and severity (Hunt \& Eisenberg, 2010) and it is imperative that universities become more proactive in the provision of support and services to facilitate early intervention with this group of students (Kim et al., 2011).

As Australian universities are now an important destination for international students we must also provide support and training for staff to increase their awareness of help seeking behaviours in students from diverse cultural backgrounds (Lui, 2009). In America and the United Kingdom 
it was identified that international students from Asia and Pacific Island students were less likely to perceive the need for or receiving assistance for mental health problems during their time at university (Eisenberg et al, 2007; Eisenberg, Golberstein \& Gollust, 2007; Turner et al., 2007). Furthermore, university life for minority students at predominately white institutions is particularly stressful and to date little is known about how student workloads further impact on this level of stress (Hunt \& Eisenberg, 2010). Language barriers add another dimension to this stress as students with lower levels of English fluency interact less easily within their new cultural settings and therefore do not adjust to university life in a new country easily (Liu, 2009).

In Australia, research in the area has documented the self-reported levels of psychological distress of "university-aged" young adults between the ages of 18 and 25 years (Leahy, et al., 2010) and the psychological distress of students attending university counselling and health services (Khawaja \& Dempsey, 2007; Stallman, 2011) . Moreover, national education data-sets do not distinguish mental health from medical or 'other' disability categories (Senate Employment Workplace Relations and Education References Committee, 2002), and government surveys of mental health and wellbeing report prevalence data of common mental disorders from the perspective of "university-aged" young adults. Consideration of the available data does, nevertheless, suggest that mental health problems are common in this population.

Referencing these data estimates derived from the most recent Australian National Mental Health and Wellbeing Survey reported that in 2007 more than one-quarter of young adults aged between 16 and 24 years (26\%) met the ICD-10 criteria for a life-time diagnosis of a mental disorder and had experienced symptoms of mental illness in the previous 12 month, with rates peaking for men aged 16 to 34 years (23\%), and women aged 16 to 24 years $(30 \%)$. These disorders were mostly anxiety disorders (15\%), followed by substance abuse disorders (13\%), and affective disorders (6\%) (Australian Bureau of Statistics, 2010). Similarly, Hickie et al., (2007) using data from two national clinical audits of general practitioners (1998-1999 and 2000-2002) estimated that between $27 \%$ and $38 \%$ of young adults (16 to 25 year olds) attending their GP during the audit period met threshold criteria for a sub-syndromal disturbance, or a full syndromal mental disorder, as determined by scores on a screening tool for common mental disorders. However, Stallman (2008) and Stallman and Shochet (2009) found that between $45 \%$ and 53\% of students attending health services across selected Queensland universities had levels of psychological distress indicative of mental disorder in the four weeks prior to accessing services, and that these students had significantly greater levels of distress than compared with reported data from the general population.

From a university perspective, the significance of these data to the Australian university community was highlighted by Professor Steven Schwartz, Vice Chancellor of Macquarie University, when he reported that $10 \%$ to $15 \%$ of university students contemplated suicide at some point in their university career (Schwartz, 2008). More generally, cross-national (Lee et al., 2009) and national epidemiological studies (Hunt et al., 2010; Kessler et al., 1995; Lee et al., 2009), as well as convenience samples of university students (Andrews \& Wilding, 2004; Hysenbegasi et al., 2005), have shown that mental health problems negatively impact academic performance, and retention and completion rates. For example, Kessler et al. (1995) in their analysis of national epidemiological data from the United States of America, estimated that $86 \%$ 
of individuals with a mental disorder withdraw from higher education before completion. In Australia, researchers have reported that levels of psychological distress were significantly associated with the number of days in which students reported they are unable to meet their work and study commitments, and the number of days in which students subjectively reported reduced capacity to fulfil their commitments:

Students experiencing very high levels of [psychological] distress were on average unable to work or study for eight days within the previous four weeks, and had on average another 9 days of reduced capacity for work resulting in some impairment for around 60\% of time (Stallman, 2008, p. 676).

Despite the considerable interference with daily life, work and/or education, research consistently shows that young adults fail to seek help or delay seeking help. For example, Stallman and Shochet (2009) reported that over one-third of university students (39\%) with significantly elevated levels of psychological distress had not consulted a health-care professional about their distress during the previous four weeks. National Australian survey data also show a relatively low use $(23 \%)$ of mental health services by young adults (Australian Bureau of Statistics, 2010).

The most frequently reported reasons for the observed low level of help-seeking in this demographic have been lack of recognition that the symptoms causing distress and interference with daily life may constitute a mental health problem (Farrer et al., 2008; Wright \& Jorm, 2009), negative attitudes toward and poor knowledge about appropriate forms of help (Kelly et al., 2007; Rickwood et al., 2005; Rickwood et al., 2007), perceived stigma (Chew-Graham et al., 2003; Martin, 2010; Yap et al., 2010), family reputation (Wynaden et al., 2005) and age (Eisenberg et al., 2007).

Khawaja and Bryden (2006) also draw attention to a body of research that suggests there are subtle differences in how negative emotional states (e.g., depression, anxiety and stress) are expressed/experienced by students in higher education. That is, these authors cite research that shows a greater prominence of cognitive symptoms (e.g., lack of concentration, pessimism, selfblame, self-dislike and lack of energy) among students with depression, than compared with the general population, and that some major somatic symptoms (e.g., changes in sleep and appetite) are less useful indicators of negative emotional states in students as they are often caused by other factors, such as social and academic schedules. Negative mood states, therefore, maybe more difficult to detect in university students, and university-aged young adults, than the general population, particularly if negative mood is not the primary reason for seeking help. Wilhelm et al., (2008) noted that people may be more willing to emphasize their somatic symptoms: consequently, non-specific symptoms such as insomnia, prolonged fatigue, headache, nausea and musculoskeletal pain are common presentations in people with depression or anxiety. This suggests that primary care providers need to be aware that the negative emotional states may be characterized by specific cognitive, motivational and social symptoms relevant to the educational environment.

Indeed, Hickie et al., (2007) reported that even when young people present in general practice with severe symptoms of mental ill-health, detection and treatment occurred at relatively low levels, for example, diagnosis: $42.6 \%$ to $52.0 \%$; treatment: $36.1 \%$ to $51.7 \%$. While reasons for 
this failure to detect and treat common mental disorders could not be delineated from this research, a lack of experience in dealing with young people in general practice, and lack of appropriate screening tools and guidelines were postulated.

The mental health profile presented by university students is, therefore, quite diverse and requires a strategic response that takes into account the needs of students dealing with the "normal" demands of higher education as well as the needs of students entering university with an emerging, or pre-existing, mental disorder (Andrews \& Wilding, 2004; Richards \& Tangney, 2008).

While Australian universities requirement to pay explicit attention to the provision of educational opportunity for students whose physical disabilities and medical conditions are covered in the Disability Discrimination Act (DDA) 1992 definition, and specific groups covered are set out in the Australian Government Access and Equity policy (2006-2008), services provided to students experiencing distress and interference with personal functioning as a result of mental ill-health require further development. The aim of this paper is to present a snap shot of these students' experiences and to highlight their specific needs within the university community. These identified needs will provide university strategic planners with information to guide service improvement in this area. These improvements include strategies to reduce the stigma attached to mental illness within the university environment; providing students with information on how to access professional help and support; designated university websites providing information on mental illness and how to access assistance; and improved education for staff to facilitate positive engagement and support to students experiencing mental health problems.

\section{Methods}

\section{Design}

This qualitative exploratory study, using a cross-sectional survey design, investigated the experiences of students at one Western Australian university who self-identified as experiencing and managing a mental health problem. Open-ended questions about the students' experience of a mental health problem were asked to allow researchers insight into the personal and contextual aspects of the self-identified experience. These insights may not easily captured by quantitative survey research methods (Holloway, 2008), which are deductive in nature. The open ended question free text format of some questions allowed students to document the experiences which were causing them concern in their own words as these experiences may not have been documented on a quantitative questionnaire format. The study adopted the broad definition of "mental health problems" to ensure that students who had not received a formal diagnosis, but who may be experiencing emerging symptoms of a mental illness, as well as those students who identified that their level of wellbeing was compromised due to high levels of stress or distress that was placing them "at risk of developing a mental illness", were covered in the survey.

The survey was offered 'online' for ease of access, and to maximize exposure to the university's student population who may be studying via different modalities. The study was approved by the University's Human Research Ethics Committee and funded through a Higher Education Equity 
Support Program grant. An information sheet was provided on the online survey access page, where respondents were advised that participation was voluntary, and that they had the right to withdraw prior to submitting their survey form. Consent to participate was implied if the survey was completed. The online survey was comprised of four sections: (1) demographic questions; (2) information regarding the participant's self-identified mental health problem; (3) impact of the participant's mental health problem on university life, and (4) information about university support services. At the end of the survey there was information on how to seek help for respondents who may not previously have spoken to a health professional about their problem or those students who were currently experiencing high levels of distress. This information included the contact numbers for University Counselling and Health Services, General practitioner networks in Western Australia, Mental health referral lines in Western Australia and Crisis Care 24 hour helpline.

\section{Procedure}

The online survey used "Questionpro Survey Software". Prior to the release date, the survey was advertised extensively by staff from Student Services and University Strategy and Planning, via the university's communications portal, and homepage. In the middle of May, a second group message was distributed via communication channels reminding students that the survey would close on the $31^{\text {st }}$ of May 2009.

\section{Measure}

The questionnaire employed a variety of dichotomous, multiple-option, and free-text response formats. The free-text questions allowed students a maximum of 1000 words to describe aspects of their mental health concerns, and its impact on their ability to complete their studies and participate in university life. The focus of this paper are selected data derived from section one and section two of the online survey. The latter consisted of 10 questions include three that were free-text items which are detailed in Table 1:

Table 1: Questions on Section 2 of the online survey

\begin{tabular}{|ll|l|}
\hline \multicolumn{1}{|c|}{ Question } & \multicolumn{1}{c|}{ Response selection } \\
\hline 1. & $\begin{array}{l}\text { Describe what you believe are your main mental health } \\
\text { problems }\end{array}$ & $\begin{array}{l}\text { Free text item response that allows for } \\
\text { descriptions of multiple presenting problems }\end{array}$ \\
\hline 2. & $\begin{array}{l}\text { Have you consulted any of the following health } \\
\text { professionals? (GP, Psychologist, Psychiatrist, } \\
\text { Counsellor, other health professional) }\end{array}$ & $\begin{array}{l}\text { If yes, please select which professional } \\
\text { If no, go to question } 10 .\end{array}$ \\
\hline 3. & $\begin{array}{l}\text { Have you been formally diagnosed with a mental health } \\
\text { problem by a health professional? }\end{array}$ & Yes/ No \\
\hline 4. & Who provided this diagnosis? & GP, Psychologist, Psychiatrist, Other health \\
\hline
\end{tabular}




\begin{tabular}{|c|c|}
\hline & professional \\
\hline 5. What was the diagnosis? & $\begin{array}{l}\text { Free text response that allows for multiple } \\
\text { descriptions of diagnoses }\end{array}$ \\
\hline 6. How long since you were first given this diagnosis? & $\begin{array}{l}<\text { one year, } 1-3 \text { years, } 4-6 \text { years, } 7-12 \text { years } \\
>12 \text { years }\end{array}$ \\
\hline $\begin{array}{l}\text { 7. Do you take prescribed medication for your mental } \\
\text { health problem? }\end{array}$ & $\begin{array}{l}\text { Not at all, rarely, sometimes, often, all the } \\
\text { time }\end{array}$ \\
\hline $\begin{array}{l}\text { 8. Is the prescribed medication helpful in managing your } \\
\text { problem? }\end{array}$ & $\begin{array}{l}\text { Not at all, rarely, sometimes, often, all the } \\
\text { time }\end{array}$ \\
\hline $\begin{array}{l}\text { 9. How much does the prescribed medication interfere with } \\
\text { your ability to complete your studies at university? }\end{array}$ & $\begin{array}{l}\text { Not at all, rarely, sometimes, often, all the } \\
\text { time }\end{array}$ \\
\hline $\begin{array}{l}\text { 10.What are the main reasons why you have not seen a } \\
\text { health professional about your mental health problem? }\end{array}$ & $\begin{array}{l}\text { Free text response that allows for multiple } \\
\text { descriptions of why the student has not seen } \\
\text { a health professional }\end{array}$ \\
\hline
\end{tabular}

\section{Participants}

During May 2009, the survey was accessed by 2737 students. However, of these only 1378 students provided complete and usable descriptions of the range of mental health problems that were causing them concern, or diagnostic information indicating that they were experiencing and managing a mental health problem. Table 2 shows that the majority of survey respondents were female $(72.1 \%)$, undergraduate $(83.7 \%)$, full-time $(76.6 \%)$, and domestic students $(85.5 \%)$.

Perhaps not surprising given the percentage of undergraduates, $66.7 \%$ reported that they had been enrolled in their current course for two years or less. The age of the sample was positively skewed, with $71.2 \%$ of students aged less than 26 years. In general, survey respondents were more likely to be female (72.1\% vs. 54.1\%), and aged between 20 and 25 years (45.6\% vs. 10.4\%), than the general student population during semester one, 2009. All teaching areas were represented in the sample: Health Sciences (38.8\%), Humanities (22.9\%), Business (19.9\%), Science \& Engineering $(16.9 \%)$, and Aboriginal Studies (0.4\%). Inter-faculty and cross-institutional enrolments accounted for another one per cent of respondents.

Table 2: Selected socio-demographics of survey respondents compared with the university student population, as at the census date 2009 , semester one

\begin{tabular}{|c|c|c|}
\hline Variable & $n=1378$ & $\mathrm{~N}=27983^{1}$ \\
\hline \multicolumn{3}{|l|}{ Gender (\%) } \\
\hline Male & $383(27.8)$ & 12853 (45.9) \\
\hline Female & $993(72.1)$ & $15130(54.1)$ \\
\hline Missing data & $2(0.1)$ & - \\
\hline \multicolumn{3}{|l|}{ Age groups (\%) } \\
\hline Less than 20 years & $353(25.6)$ & $14666(52.4)$ \\
\hline $20-25$ years & $629(45.6)$ & $2898(10.4)$ \\
\hline $26-29$ years & $126(9.1)$ & $3204(11.4)$ \\
\hline $30-39$ years & 149 (10.8) & $1737(6.2)$ \\
\hline $40-49$ years & $80(5.8)$ & $879(3.1)$ \\
\hline Over 50 years & $38(2.8)$ & 4599 (16.4) \\
\hline Missing data & $3(0.2)$ & - \\
\hline Degree type & & \\
\hline
\end{tabular}




$\begin{array}{lcc}\text { Undergraduate } & 1154(83.7) & 20837(74.5) \\ \text { Postgraduate } & 219(15.9) & 5871(20.9)^{2} \\ \text { Non-award } & - & 1275(4.5) \\ \text { Missing data } & 5(0.4) & - \\ \text { Mode of study } & 1069(77.6) & 20006(71.5) \\ \quad \text { Full-time } & 305(22.1) & 7977(28.5) \\ \text { Part-time } & 4(0.3) & - \\ \text { Missing data } & & \\ \text { Length of time enrolled in current course } & 480(34.8) & 11724(41.9) \\ \text { Less than 1 year } & 439(31.9) & 11573(41.4) \\ 1-2 \text { years } & 387(28.1) & 3723(13.3) \\ 3-4 \text { years } & 54(3.9) & 571(2.0) \\ 5-6 \text { years } & 16(1.2) & 392(1.4) \\ \text { More than } 6 \text { years } & 2(0.1) & - \\ \text { Missing data } & 1178(85.5) & 20794(74.3) \\ \text { Student type } & 190(13.8) & 7189(25.7) \\ \quad \text { Domestic (Australian \& New Zealand })^{3} & 10(0.7) & - \\ \text { International } & { }^{4} \\ \text { Missing data } & & \\ & & \\ { }^{1} \text { Students who were enrolled in more than one degree at the semester } 1,2009 \text { census date were counted } \\ \text { once. }\end{array}$

\section{Data analysis}

Due to the volume of data available, the free-text items in section two were analysed with PASW® Text Analytics for Surveys 3.0.1 (TAfS) (SPSS Inc, 2009). The analytic process adopted employed a staged and iterative approach, whereby the first stage relied upon the automatic linguistic and statistical extraction processes of TAfS, stage two involved a manual review of the extraction list to eliminate misclassification of terms (words or phrases) due to default dictionary settings, and stage three involved refinement of the dictionaries and the creation of a custom mental health library that referenced ICD-10 mental and behavioural disorders (F00-F69) (HW). Stage four involved re-extraction of terms using the refined settings, and manual categorization of data (HW). The analytic process was repeated for each free-text item. Outcomes of stages three and four were reviewed with (DW), and any discrepancies were consolidated. In the final stage, the categories were exported as coded multiple response variables into Microsoft Excel format, and then imported to SPSS Version 17.0 (SPSS Inc, 2008) and merged with demographic data.

Supplementing the above generic process, a decision frame was used to categorize extracted data in response to the key section two item "Describe what you believe are your main mental health problems". The criteria used were as follows: 
1. Terms extracted that related to the diagnosis of, treatment of, or medication for, a recognizable mental illness were accepted as definitive, and coded under the relevant diagnostic category. No further symptom-level information was coded.

2. Symptom-level terms were coded using five broad categories: (i) effects on emotions; (ii) effects on thinking; (iii) effects on behaviour; (iv) physical effects, and (v) variations usually, but not always, associated with cross-cultural differences.

3. Contextual terms were coded independently.

Using this framework it was possible to code free-text responses according to criterion one, criterion two, or criterion three; or criteria one and three, or criteria two and three. The rationale underlying this framework related directly to the existence of established mental health taxonomic systems, and the large variation in the manner descriptions were entered into the form. That is, survey respondents sometimes only provided general mental health labels without explanation (e.g., depression, bipolar, schizophrenia, etc), or provided these labels alongside symptom-level information that was insufficient to justify the label they had provided. Stand-alone symptom-level information was also often vague from a clinical perspective. Coding all these data together would, therefore, be misleading as to the range and extent of issues survey respondents must deal with.

\section{Results}

Mental health concerns of survey respondents

Initial review of the key item "Describe what you believe are your main mental health problems" showed that 14 survey respondents did not provide any text, and a further 79 survey respondents (5.4\%) did not provide text that described a mental health issue that could be analysed. For example:

I'm not particularly influenced by the labeling [sic] of mental health concerns. I believe that any mental health concerns stem from a variety of unresolved issues for individuals and do not fit into any labels...

Results of the enumerated content analysis of the remaining responses $(n=1378)$ produced coded multiple response set data that showed $83.4 \%$ described a recognizable labels for common mental disorders. These included references to: mood disorders (e.g., bipolar affective disorder, depressive disorders, manic and depressive episodes, persistent mood disorders, etc) $(n=594)$; neurotic and stress-related disorders (e.g., phobic and other anxiety disorders, generalized anxiety disorder, obsessive-compulsive disorder, and reactions to stress and adjustment disorders) $(\mathrm{n}=434)$; eating disorders $(n=38)$; hyperkinetic disorders (ADD \& ADHD) $(n=25)$; personality disorders $(n=23)$; alcohol and/or substance abuse/dependence $(\mathrm{n}=16)$; and psychotic disorders (including schizophrenia and schizoaffective disorder) $(\mathrm{n}=14)$. A further five respondents reported a number of other recognisable mental health labels (e.g., Asperger's syndrome, learning disability not otherwise specified, etc). It is important to note that information about clinical features required to diagnose these disorders was rarely presented. 
Symptom-level information was provided by $44.0 \%$ of the 1378 survey respondents (as per criterion two of the coding frame). These multiple response set data were coded using five broad categories: (i) effects on emotions; (ii) effects on thinking; (iii) effects on behaviour; (iv) physical effects, and (v) variations usually, but not always, associated with cross-cultural differences. While the symptoms described under these categories are typical of the emotions, thinking, behaviour and physical effects of depressive and neurotic, stress-related, and anxiety disorders, they may also be indicators of other disorders, such as the prodromal states for psychotic disorders, or they may be caused by other experiences associated with the normal demands of higher education. Lack of information about severity, duration, and the presence or absence of sentinel symptoms made it impossible to determine the clinical significance of the descriptions.

Of the 606 survey respondents who provided symptom-level information, the most commonly reported area impacting wellbeing were problems associated with effects on participants' thinking $(n=209)$. This category included descriptions of frequent self-criticism, self-blame, worry, pessimism, negative thinking and rumination, impaired memory and concentration, indecisiveness and confusion, tendency to believe others see you in a negative light, thoughts of death and suicide, and wishing they were dead. Loss of confidence in themselves and poor self-esteem were also included in this cluster.

Roughly the same number of respondents reported negative effects on behaviour $(\mathrm{n}=151)$ and effects on emotions $(\mathrm{n}=143)$. The symptom cluster of effects of behaviour covered descriptions of increased sensitivity and crying spells, withdrawal from others, and neglect of responsibilities, loss of interest in personal appearance, and loss of motivation. Procrastination and self-destructive behaviours (e.g., cutting, self-harm not otherwise specified, punching one-self) were also included in this cluster. Effects on emotions included reports of sadness, anxious feelings, guilt, anger, irritability, feeling tense and jumpy, feelings of apprehension or dread, mood swings, lack of emotional responsiveness, helplessness and hopelessness.

A slightly smaller number of respondents described negative physical effects $(n=105)$ that incorporated reports of chronic fatigue, lack of energy, sleeping too much or too little, overeating or loss of appetite (eating disorder not described), constipation, unplanned weight loss or gain, loss of sexual desire, unexplained aches and pains, or other physiological symptoms. Perhaps not surprising, problems with fatigue and sleep dominated this symptom cluster. The final symptom cluster (variations) covered expressions of isolation and feelings of loneliness and homesickness, as well as shame $(n=44)$. This cluster was most often reported by international students, or domestic students who lived away from home.

A substantial percentage of survey respondents reported that stress was impacting their mental wellbeing $(77.6 \%)$. These reports, provided independently or alongside clinical labels or symptomlevel information, covered unspecified stress $(n=213)$; stress associated with assignments, exams and deadlines $(\mathrm{n}=187)$; stress associated with family and social relationships, and employment $(n=172)$, and stress associated with the volume of work (all sources) $(n=171)$. Problems with time management $(n=83)$, fear of failure, or of poor academic results $(n=72)$, and financial stress $(n=70)$ were also reported. Thirty respondents also noted difficulties associated with English as a second language, or with being an international student. Seventy-one respondents noted that they felt they were particularly vulnerable to stress, and that they had poor coping skills. 
Additional information provided in the descriptors revealed 27 survey respondents had family histories that involved mental illness and/or substance abuse; and 21 had personal sex or sexuality issues that were impacting their sense of mental wellbeing. Fourteen respondents also reported personal histories that involved childhood abuse, or family violence; unspecified past traumatic experiences, and physical health issues. Often this information was provided 'as is', with no, or little, indication of how these significant issues were actually impacting their wellbeing.

Health professional consultation and formal diagnoses

Six hundred and forty-five of the 1378 survey respondents (46.8\%) with analysable data reported that they had consulted a professional regarding their concerns about their mental health (See Table 3).

Table 3: Survey respondents who had consulted a health professional regarding concerns about their mental health

Person consulted

General practitioners

Psychologist

Psychiatrist

Counsellor

Other health professional

Total
Percent

29.6

28.7

18.5

17.6

5.6

100.00

Four hundred and one of the 645 survey respondents who had consulted someone indicated that they had received a formal diagnosis $(62.2 \%), 152$ had not received a formal diagnosis $(23.6 \%)$, and a further 64 were unsure whether or not they had been formally diagnosed with any mental health problem $(9.9 \%)$. There were missing data for 28 respondents $(4.3 \%)$.

The most common diagnosis reported by these survey respondents was depressive disorder $(72.7 \%)$, followed by anxiety disorder $(26.0 \%)$, stress and adjustment disorder $(7.9 \%)$, bipolar affective disorder (5.7\%), and hyperkinetic (attentional) disorders (5.4\%). A small number of respondents did not provide any diagnostic information, despite reporting they had received a formal diagnosis $(2.5 \%)$. Of those respondents who had received a formal diagnosis, $35.4 \%$ had received their diagnosis between one and three years before the date of the survey. Given the percentage of respondents who had just received their diagnosis in the last three years were undergraduates, these data suggest the onset of mental health problems occurred within the same time-frame as commencement at university.

Reasons for not consulting a health professional

Of the 720 survey respondents who indicated they had not consulted a health professional about their mental health concerns, $627(87.1 \%)$ provided free-text comments regarding their reasons for not doing so. Enumerated content analysis of this text produced a multiple response set that showed $41.3 \%$ of respondents were unsure whether their problems were serious enough to warrant 
consulting a health professional, or even whether they had problems for which it was necessary to consult someone. For example:

... I have 'episodes' and once these episodes are over I convince myself that it was the last one, and that seeing someone would just seem stupid ...

... not constant enough, only a little every now and again. [I am] ashamed, not really a real disorder, don't want to find the reason behind it. [I] think I can manage it myself, don't want to go on any medications just because I'm a bit prone to crying. [I am] sure it's just a phase ...

... not serious enough, surely it's for the people with suicidal thoughts ...

Indeed, some respondents provided text that suggested they were hoping the survey would tell them if they had a problem that needed treatment. For example:

I don't know if I have a mental health problem. That is why I'm taking this survey to see if I do.

However, a substantial percentage of respondents (i.e., 18.0\%) reported that they had not sought the assistance of a health professional because they felt they were able to deal with their problems on their own. For example:

... I was bought up in an environment where you handle your own problems ...

... I've always dealt with my own problems, and I don't like people thinking that I'm weak, or can't cope ...

Although, about one-quarter of respondents (i.e., 25.3\%) also noted that they had not sought help because they were afraid, anxious, embarrassed, or ashamed to do so:

... I'm afraid they'll tell me I'm depressed...

... I am afraid they will judge me, or that there will be nothing wrong, and they will just think I am seeking attention, or trying to invent problems ...

... afraid of not being able to portray what is going on, and afraid that the professional might think it is nothing to worry about, even though I have been in this state for a few years...

... it is stupid to do so, it merely goes on your record and then you are excluded from working in certain jobs

Lack of time (22.0\%) and the potential cost of treatment $(12.3 \%)$ were also reported as important reasons participants did not seek help from a health professional. Issues of service availability and perceived capacity of health professionals to help were reported by about eight percent of respondents.

\section{Discussion}

The research findings from a self-selected group of university students, provides an insight into university students' symptoms and experiences with mental health problems and the resources they access. While the sampling approach used means that findings cannot be generalised they add to 
existing knowledge in the area and are useful for informing services at the university. Universities, like other communities, contain people who are experiencing a range of mental health problems that impact on their ability to engage fully in society. Moreover, mental health problems impact negatively on students' academic performance as well as their completion and retention rates (Andrews \& Wilding, 2004; Hysenbegasi et al., 2005). A better understanding of the unmet needs of this "at risk student group" allows universities to enhance services and support to them during this critical time (Eisenberg et al, 2007). Support to complete their program and move into employment is crucial to these students' wellbeing as research has shown that employment will have a profound effect on more of their life domains than almost any other medical or social intervention (Boardman et al., 2003; Dunn et al., 2008). Employment is also central to the recovery process and to meet their future life goals and challenges (Lester \& Gask, 2006).

As stated previously, an additional 1359 students accessed but provided insufficient data to be included in this study. While the researchers are unable to confirm that these students accessed the survey to find guidance for their mental health problems, this premise is supported by comments left by some students. This highlights the fact that significant numbers of Australians aged between 16-24 years continue to struggle with life as a result of an emerging or undiagnosed mental disorder (Australian Health Ministers, 2003). Stigma remains a major factor that keeps them from seeking help. As a result these young people continue to live with the burden of an untreated disorder even though early intervention and treatment is the key to positive outcomes (Substance Abuse and Mental Health Services Administration, 2006). In addition, as many universities now have large international student populations, it is important that all staff have a knowledge and understanding of different health belief systems in relation to mental illness. Protection of family reputation is often more important to some people than seeking assistance for their problems (Wynaden et al., 2005). Access to confidential and secure pathways to assistance, for example, online self-help programs monitored through established Counselling Services may build trusting relationships and future engagement with these students.

Universities strategic plans in addressing the area of students and culture should incorporate strategies that decrease discrimination and stigma towards mental illness. Again, services that provide "at risk" students with personal security and avenues to seek help and support must be promoted and ongoing collaboration with these organizations is essential. Headspace - the National Youth Mental Health Foundation is one such avenue that provides young people with support and security at centres located throughout Australia (Headspace, 2011). In Australia a "Mental Health Week" is celebrated each year as part of the national calendar. This week should be officially celebrated within universities as a way of further de-stigmatising mental illness. It is also a significant way to promote acceptance in all students of the range of physical and mental diversity within the university population.

Many students with mental health problem may disclose their problems to academic or support staff. Therefore all staff, particularly those who have regular contact with students, should have the knowledge and skills to engage and to support them to obtain further assistance. "Mental Health First Aid" is an example of a program that can assist university staff to provide help to a person until appropriate professional treatment is received or until the crisis resolves (Mental Health First Aid, 2007). Staff attendance at such programs should be supported by university management. 
University websites can also provide information for staff and students on how to support and assist students who self-disclose to them.

The students who responded to this survey have provided valuable insights into university life for students who are struggling with a mental health problem. As mental illness is identified by the World Health Organisation (2001) as one of the largest global health issues over the next 20 years it is important for universities to continue to work to improve campus life, learning experiences and educational outcomes for these students.

\section{Limitation}

While the online mode of delivery offered the potential to reduce barriers to participation because of the disinhibiting effect offered by online anonymity the potential for possible misreading of written communications (Richards \& Tangney, 2008) due to the use of idiosyncratic expressions, as well as the lack of information about severity, duration, and the presence or absence of sentinel symptoms was an inherent limitation of this study.

\section{References}

Andrews, B., \& Wilding, J. M. (2004). The relation of depression and anxiety to life-stress and achievement in students. British Journal of Psychology, 95, 509-521.

Australian Bureau of Statistics. (2010). Mental health of young people. Australia, 2007 [ABS Catalogue No. 4840.0.55.001]. Belconnen, ACT: Australian Bureau of Statistics. Retrieved, $26^{\text {th }}$ August 2010, from http://www.ausstats.abs.gov.au/Ausstats/subscriber.nsf/0/79915374519C710DCA25776C001CB3AC/\$File/4840 055001_2007.pdf.

Australian Government Department of Immigration and Citizenship (2009). Access and equity report in government services 2006-2008. Canberra: Australian Government.

Australian Health Ministers (2003). National mental health plan 2003-2008. Canberra: Australian Government Department of Health and Aging.

Boardman, J., Grove, B., Perkins, R. \& Shepherd, G. Work and employment for people with a psychiatric disability. British Journal of Psychiatry, 182, 467-468.

Chew Graham, C., Rogers, A. \& Yassin, N. (2003). 'I wouldn't want it on my CV or their records': medical students' experiences of help-seeking for mental health problems. Medical Education, 37, 873-880.

Dunn, E., Wewiorski, N. \& Rogers, E. (2008). The meaning and importance of employment to people with a serious mental illness: Results of a qualitative study. Psychiatric Rehabilitation Journal, 32(1), 59-62.

Eisenberg, D. (2007). Help-seeking and access to mental health care in a university student population. Medical Care, 45(7), 594-600.

Eisenberg, D., Golberstein, E \& Gollust, S. (2007). Help-seeking and access to mental health care in a university student population. Medical care, 45(7), 594-601.

Eisenberg, D., Gollust, S., Golberstein, E., \& Hefner, J. (2007). Prevalence and correlates of depression, anxiety, and suicidality among university students. American Journal of Orthopsychiatry,77(4), 534-542.

Farrer, L., Leach, L., Griffiths, K., Christensen, H., \& Jorm, A. (2008). Age differences in mental health literacy. BMC Public Health, 8(1), 125.

Headspace National Youth Mental Health Foundation (2011). Retrieved, $20^{\text {th }}$ May 2011, from www.headspace.com.au.

Hickie, I. B., Fogarty, A. S., Davenport, T. A., Luscombe, G. M., \& Burns, J. (2007). Responding to experiences of young people with common mental health problems attending Australian general practice. Medical Journal of Australia, 187(7), S47-S52.

Holloway, I. (2008). A-Z of qualitative research in healthcare (2nd ed.). UK: Wiley-Blackwell. 
Hunt, J., \& Eisenberg, D. (2010). Mental health problems and help-seeking behaviour among college students. Journal of Adolescent Health, 46, 3-10.

Hunt, J., Eisenberg, D., \& Kilbourne, A. M. (2010). Consequences of receipt of a psychiatric diagnosis for completion of college. Psychiatric Services, 61(4), 399-404.

Hysenbegasi, A., Hass, S. L., \& Rowland, C. R. (2005). The impact of depression on the academic productivity of university students. The Journal of Mental Health Policy and Economics, 8, 145-151.

Kelly, C. M., Jorm, A. F., \& Wright, A. (2007). Improving mental health literacy as a strategy to facilitate early intervention for mental disorders. Medical Journal of Australia, 187(7), s26-s30.

Kessler, R. C., Foster, C. L., Saunders, W. B., \& Stang, P. E. (1995). Social consequences of psychiatric disorders, I: Educational attainment. American Journal of Psychiatry, 152(7), 1026-1032.

Kessler, R. C., Angermeyer, M., Anthony, J. C., et al. (2007). Lifetime prevalence and age-of-onset distributions of mental disorders in the World Health Organisation's world mental health survey initiative. World Psychiatry, 6(3), 168-176.

Khawaja, N. G., \& Bryden, K. J. (2006). The development and psychometric investigation of the university student depression inventory. Journal of Affective Disorders, 96(1-2).

Khawaja, N.G \& Dempsey, J. (2007). Psychological distress in international university students: An Australian study. Australian Journal of Guidance and Counselling, 17(1), 13-27.

Kim, E., Coumar, A., Lober, W., \& Kim, Y. (2011). Addressing mental health epidemic amoung university students via web-based, self-screening, and referral system: A preliminary study. IEEE Transactions on Information Technology in Biomedicine 15(2), 301-307.

Leahy, C., Peterson, R., Wilson, I, Newby, J, Tonkin, A \& Turnbull, D (2010). Distress levels and self-reported treatment rates for medicine, law, psychology and mechanical engineering tertiary students: Cross sectional study, Australian and New Zealand Journal of Psychiatry, 44(7), 608-615.

Lee, S., Tsang, A., Breslau, J., et al. (2009). Mental disorders and termination of education in high-income and lowand middle-income countries: epidemiological study. The British Journal of Psychiatry, 194(5), 411-417.

Lester, H. \& Gask, L. (2006). Delivering medical care to patients with serious mental illness or promoting a collaborative model of recovery. British Journal of Psychiatry, 188, 401-402.

Liu, M. (2009). Addressing the mental health problems of Chinese international college students in the United States. Advances in Social Work, 10(1), 69-86.

Martin, J. M. (2010). Stigma and student mental health in higher education. Higher Education Research \& Development, 29(3), 259 - 274.

Mental Health First Aid (2007). What is mental health first aid? Retrieved, $25^{\text {th }}$ May 2011, from http://www.mhfa.com.au/cms/.

Palmer, S., \& Puri, A. (2006). Coping with stress at university: A survival guide. London, United Kingdom: Sage Publishing.

Richards, D., \& Tangney, B. (2008). An informal online learning community for student mental health at university: a preliminary investigation. British Journal of Guidance \& Counselling, 36(1), 81 - 97.

Rickwood, D., Deane, F. P., Wilson, C. J., \& Ciarrochi, J. (2005). Young people's help-seeking for mental health problems. Australian e-Journal for the Advancement of Mental Health, 4(3 (supplement).

Rickwood, D. J., Deane, F. P., \& Wilson, C. J. (2007). When and how do young people seek professional help for mental health problems. Medical Journal of Australia, 187(7), S35-S39.

Schwartz, S. (2008, $20^{\text {th }}$ February). Don't fail your friends. The Australian: Higher Education Section. Retrieved June 2009, from http://www.vc.mq.edu.au/press-coverage/press-coverage610.pdf

Senate employment workplace relations and education references committee. (2002). Education of students with disabilities. Canberra: Commonwealth of Australia.

Stallman, H. M. (2008). Prevalence of psychological distress in university students - Implications for service delivery. Australian Family Physician, 37(8), 673-677.

Stallman, H. M., \& Shochet, I. (2009). Prevalence of mental health problems in Australian university health services. Australian Psychologist, 44(2), 122 - 127.

Substance abuse and mental health services administration (2006). Developing a stigma reduction initiative. SAMHSA PubNo SMA-4176. Rockville, MD: Centre for mental health services, substance abuse and mental health services administration.

Turner, A., Hammond, C., Gilchrist, M. \& Barlow, J. (2007). Coventry university students' experiences of mental health problems, Counselling Psychology Quarterly, 20(3), 247-252. 
World Health Organisation (2001). The World Health Report 2001: Mental health- new understanding, new hope. Geneva: WHO.

Wynaden, D., Chapman, R., Orb, A., McGowan, S., Yeak, S., \& Zeeman, Z. (2005). Factors that influence people from Asian communities' access to and delivery of mental health care. International Journal of Mental Health Nursing (14), 88-95.

Copyright @ 2011 Dianne Wynaden, Helen Wichmann and Sean Murray. The authors assign to HERDSA and educational non-profit institutions a non-exclusive license to use this document for personal use and in courses of instruction provided that the article is used in full and this copyright statement is reproduced. The authors also grant a non-exclusive license to HERDSA to publish this document in full on the World Wide Web (prime site and mirrors) and within the portable electronic format HERDSA 2011 conference proceedings. Any other usage is prohibited without the express permission of the authors. 